\title{
OBTENÇÃO DE DADOS DE EQUILÍBRIO DE SISTEMAS AQUOSOS BIFÁSICOS FORMADOS POR ÁLCOOL E SAIS PARA EXTRAÇÃO DE CORANTES TÊXTEIS
}

\author{
J. G. PIMENTEL ${ }^{1 *}$, S. F. BICALHO ${ }^{2}$, O. R. R. GANDOLFI ${ }^{1}$, R. C. F. BONOMO ${ }^{3}$, R. \\ C. I. FONTAN ${ }^{3}$, L. B. RODRIGUES ${ }^{4}$ \\ ${ }^{1}$ Universidade Estadual do Sudoeste da Bahia, Laboratório de Engenharia de \\ Processos \\ ${ }^{2}$ Faculdade de Tecnologia e Ciências, Departamento de Engenharia Civil \\ ${ }^{3}$ Universidade Estadual do Sudoeste da Bahia, Departamento de Tecnologia Rural e \\ Animal \\ ${ }^{4}$ Universidade Estadual do Sudoeste da Bahia, Núcleo de Inovação Tecnológica \\ *e-mail: juliana.eng@outlook.com
}

\begin{abstract}
RESUMO
Os problemas ambientais são cada vez mais debatidos nas últmas décadas. Nesse contexto, temos a poluição das águas, destacando aqui os despejos de efluentes têxteis; com um grande volume e elevada coloração. Corantes são compostos problemáticos nesses efluentes, provocando poluição visual, alterações em ciclos biológicos afetando principalmente o processo de fotossíntese. Os crescentes aumentos nos custos de tratamento e disposição final de resíduos e subprodutos do tratamento de efluentes tem levado a uma maior atenção para tecnologias mais limpa e eficiente, destacando-se o processo de separação de compostos oriundo da ramificação da extração líquidolíquido, o Sistemas Aquosos Bifásicos (SABs). Esse trabalho teve por objetivo a construção das binodais, para sistemas aquosos bifásicos compostos por álcool Isopropílico + Sulfato de Sódio/Sulfato de Magnésio e água, sendo esse último, o constituinte de maior concentração; analisados nas temperaturas de $(20$ e 50$){ }^{\circ} \mathrm{C}$. O efeito da temperatura nas curvas binodais foi analisado tendo em vista os dois tipos de sais utilizados, não havendo diferenças relevantes da área bifásica com o aumento da temperatura e diferença de sal para ambos os sistemas utilizados. A pesquisa visa o estudo da técnica de separação de moléculas de corante têxteis tornando possível reciclar o efluente tratado no processo de produção e, sempre que possível, também os materiais com valor comercial contidos no efluente.
\end{abstract}

\section{INTRODUÇÃO}

Às questões associadas ao meio ambiente são cada vez mais debatidas nas últimas décadas. O nível de degradação e o consumo exacerbado dos recursos disponíveis na natureza estão fazendo com que a preocupação com a mesma seja mais valorizada, indo assim em busca de melhorias e soluções frente a essas situações. $\mathrm{O}$ descarte inadequado de resíduos no meio ambiente caracteriza-se como uma das problemáticas na atual sociedade. Neste contexto, encontra-se a poluição das águas, comumente contaminadas por resíduos urbanos; metais pesados oriundos de 
processos industriais (AYDIN, BULUT, YERLIKAYA, 2008) bem como efluentes provenientes de indústrias têxteis (GUPTA, SUHAS, 2009).

Desse modo, a indústria têxtil é uma das maiores geradoras de efluentes líquidos, devido à grande quantidade de água utilizada nos processos de acabamento. Os efluentes provenientes dessas indústrias são complexos, contendo uma ampla variedade de corantes, dentre outros produtos. Em geral, cerca de 5 a $20 \%$ do corante é perdido no processo de tingimento, causado pela incompleta fixação deste nas fibras têxteis durante a lavagem do tecido (PASCOAL; TREMILIOSI-FILHO, 2005). Com relação ao Brasil, estima-se que mais de 20 mil toneladas destes produtos são anualmente consumidas pelas indústrias do setor têxtil (DALLAGO, SMANIOTTO, OLIVEIRA 2005).

Corantes são identificados como os compostos mais problemáticos nos efluentes têxteis devido a sua alta solubilidade na água e baixa degradabilidade (BALAN, MONTEIRO 2001; TOH et al, 2003). Além de tóxicos, certas classes de corantes, assim como seus subprodutos, podem ser carcinogênicos e/ou mutagênicos (ALI, AHMED, HAQ, 2009).

A poluição de corpos de água com estes compostos provocam alterações em ciclos biológicos, com formação de espuma na superfície, afetando principalmente processos de fotossíntese; bem como modificação da coloração natural das águas. Além do exposto; as regulamentações ambientais ficaram mais restritiva, com medidas para o descarte de efluentes, padrões de emissão no corpo receptor, bem como crescentes aumentos nos custos de tratamento e disposição final de resíduos e subprodutos do tratamento de efluentes tem mostrado a necessidade e busca por novas alternativas mais limpas e eficientes.

Portanto, nos últimos anos, a necessidade de técnicas de separação efetivas, eficientes e econômicas em larga escala; tornam-se preferidas tecnologias de tratamento com possibilidade de reciclar o efluente tratado no processo de produção e, sempre que possível, também os materiais com valor comercial contidos no efluente (MELO, 2008; SAUER, 2002). E entre os processos existentes para a separação de compostos moleculares vem se destacando uma ramificação da extração líquido-líquido chamada extração por Sistemas Aquosos Bifásicos (SAB's), operação muito utilizada na indústria química como técnica de separação.

Os SAB's são formados por espécies químicas que, quando misturadas em determinadas faixas de composição e temperatura, dividem-se em duas fases com composições diferentes, em equilíbrio termodinâmico, cujas fases são constituídas marjoritariamente por água. Solutos se distribuem entre as duas fases, dependendo da sua afinidade relativa por cada uma das fases individuais (Albertsson, 1986), sendo quantificados por meio do coeficiente de partição K.

Fatores como constituição, tamanho e estrutura molecular dos constituintes do sistema, temperatura, natureza e tamanho da partícula alvo, $\mathrm{pH}$ e natureza do eletrólito do sistema bifásico influencia na separação de fases do SAB's e, consequentemente, o processo extrativo de um determinado compostos (BANK et al., 2003).

Os sistemas podem ser compostos basicamente por polímeros/polímeros (LI e CAO, 2010); polímero/sal (MOATTAR e HASHEMI, 2012); líquidos iônicos/sal (HAN et al., 2014) e micromoléculas orgânicas hidrofílicas/sal (MOATTAR e KANDE, 2012).

O presente relatório teve como objetivo apresentar os dados de equilíbrio dos sistemas formados por álcool isopropílico + sulfato de magnésio/ sulfato de sódio + água nas temperaturas $(20$ e 50$){ }^{\circ} \mathrm{C}$. Em seguida 
objetiva-se a construção das linhas de amarração, gerando dados experimentais para utilização na posterior partição da molécula de interesse, corantes têxteis.

\subsection{Efluente Têxtil: A Extração do Corante como uma Alternativa de Tecnologia Limpa}

Métodos para remoção da cor das águas de rejeito têm recebido enorme atenção nos últimos anos (GUARATINI, ZANONI, 1999). De um modo geral, a efetividade da remoção da cor pode ser avaliada por um padrão espectrofotométricamente permitido, definido na literatura (COOPER, 1993) o qual pode ser usado para controlar a diluição do corante nas águas dos rios. Assim, através da comparação direta entre absorbância da amostra de um efluente e o padrão de qualidade requerido para coloração em rios, é possível avaliar o grau de contaminação previsto. Entretanto, a níveis não detectáveis em escala espectrofotométrica, o problema é mais sério e envolve acumulação, biodisponibilidade, etc (GUARATINI, ZANONI, 1999).

Como alternativa, surge à possibilidade das empresas adotarem tecnologias limpas, que são justificáveis à medida que podem levar a um aumento de produtividade, resultante da redução de custos, e à racionalização dos desperdícios no âmbito dos processos produtivos (GETZNER, 2002).

Os corantes têxteis são considerados extremamente perigosos pela sua toxicidade e por apresentarem baixa taxa de degradabilidade. Desse modo o esgoto da indústria têxtil tem sido taxado como o mais poluente entre os setores industriais em termos de volume e composição de efluentes. Em adição ao efeito visual e ao efeito adverso dos corantes em termos de impacto; a cor interfere na transmissão da luz solar para dentro da corrente de água, prejudicando a fotossíntese que ocorre nesse local e aumento da Demanda Química de Oxigênio (DQO), muitos corantes são tóxicos, mutagênicos e carcinogênicos (GUARATINI e ZANONI, 1999). Outro problema relacionado aos corantes é que alguns apresentam em sua composição metais pesados (cromo, cobalto, cobre, cádmio, níquel e outros) que são tóxicos à fauna e flora aquática (MACHADO, 2007).

Dessa forma, na indústria de beneficiamento têxtil, são cada vez mais frequentes medidas internas para o tratamento de efluentes. Nesse caso, são preferidas tecnologias de tratamento que tornam possível reciclar o efluente tratado no processo de produção e, sempre que possível, também os materiais com valor comercial contidos no efluente (MELO, 2008; SAUER, 2002).

A técnica de extração líquido-líquido, mais precisamente extração por Sistemas Aquosos Bifásicos (SAB's), utiliza-se da separação e purificação de biomoléculas, caracterizado como um dos recentes avanços no desenvolvimento da indústria biotecnológica. Os sistemas aquosos bifásicos são conhecidos desde o final do século XIX, quando Beijerinck percebeu a separação espontânea em duas fases liquidas limpidas ao misturar soluções aquosas de gelatina com ágar ou amido solúvel (REIS, 2012). Constitui-se assim, de um eficiente método para extração de produtos de misturas complexas, formado por misturas de espécies quimicamente distintas em concentrações além das definidas pela zona de transição de fases, também, em certas concentrações de composição e temperaturas.

Caracteriza-se por ser um processo de biosseparação eficiente, efetivo e econômico em larga escala, que permitam atingir elevado grau de pureza e rendimento de recuperação, mantendo a atividade biológica da molécula. Aém de sua utilização como um método alternativo, em substituição àqueles que empregam solventes orgânicos, sendo completamente viável e vantajoso devido a sua não toxicidade. 


\subsection{Sistemas Aquosos Bifásicos}

A formação dos Sistemas Aquosos Bifásicos é conhecida desde o final do século 19. Porém, o emprego dos SAB`s se concretizou em $1956 \mathrm{com}$ as pesquisas do bioquímico Albertsson que percebeu o potencial de utilização dos sistemas bifásicos aquosos polímero/polímero e polímero/sal para separações de células, particulados celulares e de proteínas (ALBERTSSON, 1956; ALBERTSSON, 1958; ALBERTSSON, 1959). Desde então, têm sido sugeridos como alternativa para purificação de compostos biotecnológicos e, mais recentemente, para a simulação de soluções aquosas complexas, como alimentos, remoção de cor em efluentes têxteis; poluentes orgânicos proveniente do meio ambiente (Rogers et al., 1998) e íons metálicos e aromáticos de petróleo (Hatti-Kaul, 2000);

Em um sistema aquoso bifásico, quando as espécies químicas (polieletrólitos, polímeros, líquidos iônicos, entre outras) são misturadas em determinadas composições e tempertura dividem-se em duas fases de composições diferentes, que se encontram em equilíbrio termodinâmico. As fases apresentam propriedades termodinâmicas intensivas, como índice de refração, composição e densidade. Mas quando as duas fases estão em equilíbrio, não existe troca resultante de matéria e energia entre as fases. Essas fases são separadas por uma interface, que é a região onde as propriedades termodinâmicas intensivas de cada fase transitam para valores diferentes, sempre tendendo ao valor daquela propriedade no seio da outra fase em equilibrio (CARVALHO et al., 2007).

Segundo Guo et al. (2012), com base nas composições dos Sistemas Aquosos Bifásicos, estes podem ser constituídos basicamente por: polímeros, líquidos iônicos, surfactantes, e alcoóis hidrofílicos. Entre esses sistemas mencionados acima, os líquidos iônicos apresentam uma grande desvantagem devido ao alto preço, assim como os polímeros partilha a mesma desvantagem adicionado à sua elevada viscosidade para alguns fins (TIANWEI, QUIN, QUIANG, 2002). Já essas limitações foram superadas pelos sistemas à base de alcoóis hidrofílicos, que têm as vantagens de apresentar baixo custo e simplificação de recuperação e reciclagem do produto a partir da fase rica em álcool (WANG et al., 2010).

\section{MATERIAL E MÉTODOS}

\subsection{Determinação Experimental das Curvas Binodais}

Foram obtidas as curvas binodais com os sistemas, álcool isopropílico (Fmaia) mais os sais sulfato de sódio e sulfato de magnésio (CINÈTICA, Brasil) e água destilada, nas temperaturas $(20 \text { e } 50)^{\circ} \mathrm{C}$. Utilizou-se a técnica turbidimétrica.

$\mathrm{Na}$ construção das curvas binodais, os tubos utilizados com as concentrações neles colocadas, dos sais, álcool e água destilada; cada tubo com seu respectivo sal foram vigorosamente agitados em um vórtex e colocados no banho termostático.

As soluções estoque utlizadas no experimento foram feitas na concentração de $25 \%(\mathrm{~m} / \mathrm{m})$ para ambos os sais e o álcool com grau de pureza $99,5 \%$.

As quantidades adequadas dos sais, do álcool e água, para a construção da binodal, foram pesadas em balança analítica (BEL engineering) com precisão de $\pm 0,0001 \mathrm{~kg}$. A temperatura foi controlada com uma precisão de $\pm 0,02^{\circ} \mathrm{C}$ utilizando o banho termostático (TE184 da TECNAL).

\section{RESULTADOS E DISCUSSÕES}

Foram realizados os estudos do efeito da temperatura e dos tipos de sais com a construção das binodais. $\mathrm{O}$ efeito da temperatura varia de acordo com o tipo de 
sistema, polímero-polímero, polímero-sal, álcool-sal, líquidos iônicos-sal, entre outros. Pereira (2008) ao estudar o sistema PEG e dextrana, constatou que com o aumento da temperatura era necessária uma concentração maior dos polímeros para a separação das fases. Já LOH (2008) observou ao estudar sistemas contendo PEG e sal, que ocorre justamente o efeito contrário ao observado por Pereira (2008), afirmando que em temperaturas maiores ou próximas à ambiente a separação das fases do sistema foi facilitada. Com os trabalhos envolvendo álcool e sal observou-se que a temperatura não modificou o comportamento das binodais Wenlu Guo et al.(2012) e Ziyan Feng et al. (2011), ou seja obteve comportamento totalmente diferentes dos outros sistemas contidos na literatura.

Os resultados desse trabalho verificouse que houve pouca mudança das curvas de equlíbrio com o aumento da temperatura; as mesmas chegaram até se conincidirem, mesmo com a diferença de temperatura, com pequena mudança de comportamento à medida, podendo ser comprovado através do gráfico da figura 1 . Ou seja, a temperatura não teve influencia significativa nas binodais, $o$ qual é diferente dos SAB's com polímero/sal e líquido iônico/sal. Nos SAB's feito por polímeros/sal, o aumento da temperatura faz com que haja a expansão da área bifásica (XIE et al., 2010) e no sistema feito com líquido iônico/sal o aumento da temperatura provoca a diminuição da área bifásica (YU et al., 2011).

Para a comparação do efeito dos sais nos sistemas Ananthapadmanabhan e Goddard (1987) estudaram sistemas formados por PEG 3350 e diferentes ânions em sais de sódio ou diferentes metais em sais de sulfato, concluindo que em relação à indução para formação de sistemas aquosos bifásicos os ânions dos sais de sódio são classificados na ordem decrescente: $\mathrm{PO}_{4}{ }^{-3}>\mathrm{C}_{6} \mathrm{H}_{5} \mathrm{O}_{7}{ }^{-3}>\mathrm{SO}_{4}{ }^{-2}$ $>\mathrm{CO}_{3}^{-2}>\mathrm{OH}^{-}$. Em relação à tendência da formação de sistemas dos sais de sulfato, a seguinte ordem decrescente foi estabelecida: $\mathrm{Al}>\mathrm{Na}>\mathrm{Mg}>\mathrm{Fe}>\mathrm{Zn}>\mathrm{NH}_{4}>\mathrm{Li}$.

As causas e os efeitos de atração polar de um sal dissolvido de um componente de uma água solução de eletrólito não foram explicadas por várias teorias. Estas teorias podem ser explicadas em relação à hidratação, a interação eletrostática, a pressão interna e forças de Vanderwaals.

Figura 1. Diagramas de equilíbrio de fases para sistemas Álcool Isopropílico/Sulfato de Magnésio e de Sódio nas temperaturas de $20^{\circ} \mathrm{C}(\bullet)$ e $50^{\circ} \mathrm{C}$

$(\square)$, respectivamente.

Binodais Álcool Isoproprílico + Sulfato de Magnésio + $(20 \text { e } 50)^{\circ} \mathrm{C}$

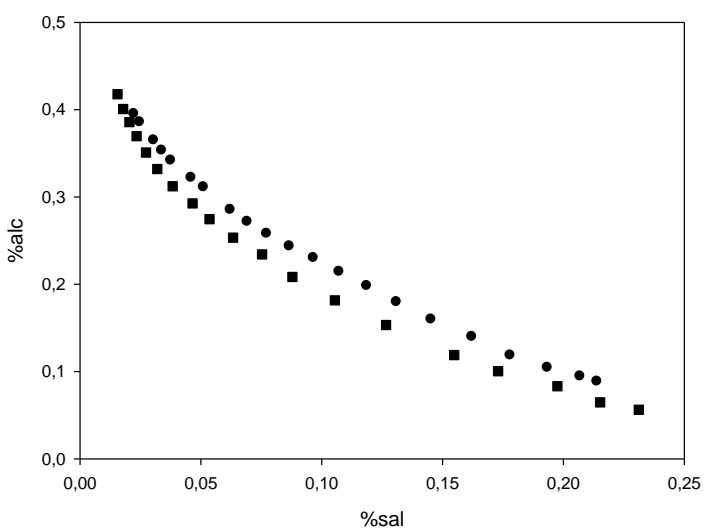

- $\quad \%$ sal Mg $20^{\circ} \mathrm{C}$ vs \%alc
- $\%$ sal Mg $50^{\circ} \mathrm{C}$ vs \%alc

Binodais Álcool Isopropílico + Sulfato de Sódio + $\left(20\right.$ e 50) ${ }^{\circ} \mathrm{C}$

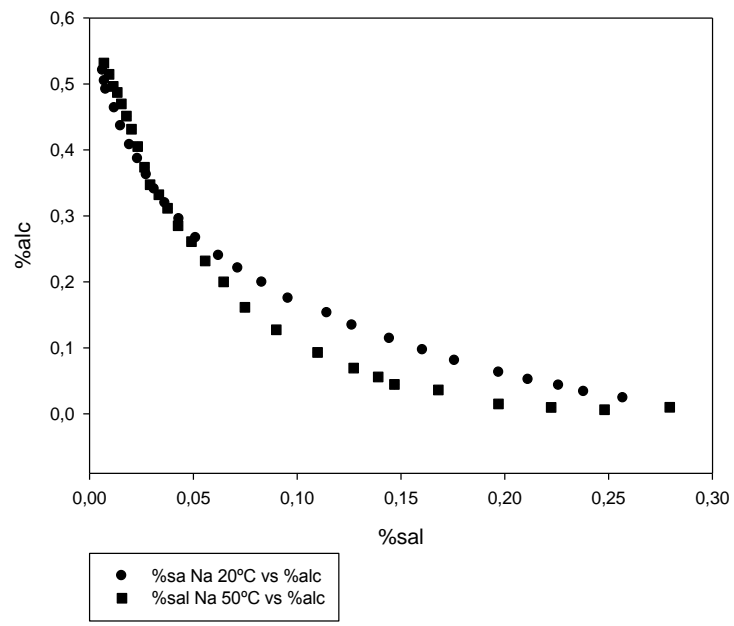

Fonte: SigmaPlot 11.0; J.G. PIMENTEL (2015) 
A presença do sal pode aumentar ou reduzir a volatilidade relativa do não eletrólito ou em casos extremos, provocar a formação das duas fases líquidas. Os efeitos observados dependem da natureza e concentração do sal e, tanto o não eletrólito. Geralmente o sal tem um efeito considerável sobre o solvente o qual é adicionado KHUNTIA e SWAM (2007).

Dessa forma os sais Sulfato de Sódio $\left(\mathrm{NaSO}_{4}\right)$ e o de Magnésio $\left(\mathrm{MgSO}_{4}\right)$ em ambas temperaturas analisadas, $(20 \text { e } 50)^{\circ} \mathrm{C}$, observou-se uma ligeira diminuição da região bifásica para a curva realizada com o Sulfato de Magnésio, conforme os gráfico da figura 2 apresentada abaixo. Uma possível explicação teórica a esse comportamento pode ser analisado considerando dois íons de diferentes raios e, portanto diferentes densidades de carga, o íon de menor raio (e maior densidade de carga), irá interagir com o polímero, não eletrolítico, em maior proporção, favorecendo a interação, resultando na maior quantidade de sal necessária à saturação da cadeia do polímero e na diminuição da região bifásica, (CARVALHO, 2004).

Os dados experimentais das binodais do Álcool Isopropílico + Sulfatos de Sódio/Magnésio + H2O às temperaturas $20 \mathrm{e}$ $50{ }^{\circ} \mathrm{C}$ foram apresentados em tabelas. Uma equação empírica, equação 1 foi usada para correlacionar os dados das binodais, está equação foi usada com sucesso para Líquidos iônicos - sal SAB's (WANG et al, 2010) e Álcools hidrofílicos - sal SAB's (ZHAO et al, 2011).

$w_{1}=\exp \left(a+b w_{2}^{0,5}+c w_{2}+d w_{2}^{2}\right)$

Onde $w_{1}$ é a fração mássica de álcool hidrofílico, $w_{2}$ é a fração mássica de sal, e os coeficientes a, b, c e d são parâmetros apropriados. Estes parâmetros foram escolhidos de acordo ao coeficiente de correlação (R) que estão apresentados na tabela 1:
TABELA 1. Valores dos parâmetros da equação (1) para o Álcool isopropílico $+\mathrm{Na}_{2} \mathrm{SO}_{4} / \mathrm{MgSO}_{4}$ nas temperaturas de 20 e $50^{\circ} \mathrm{C}$.

\begin{tabular}{cccc}
\hline $\mathrm{Sal}$ & $\mathrm{a}$ & $\mathrm{b}$ & $\mathrm{c}$ \\
\hline $\mathbf{2 0} \mathbf{C}$ & & & \\
$\mathrm{Na}_{2} \mathrm{SO}_{4}$ & $-0,3066$ & $-4,4584$ & 1,3692 \\
$\mathrm{MgSO}_{4}$ & $--0,4876$ & $-3,3968$ & 2,6917 \\
$\mathbf{5 0}^{\circ} \mathbf{C}$ & & & \\
$\mathrm{Na}_{2} \mathrm{SO}_{4}$ & $-0,4893$ & $-0,1019$ & $-17,4337$ \\
$\mathrm{MgSO}_{4}$ & $-0,3129$ & $-5,1675$ & 5,3453 \\
\hline \multicolumn{5}{c}{$\mathrm{d}$} & $\mathrm{R}^{2}$ & $\mathrm{Sd}$ \\
\hline $\mathrm{Sal}^{\mathbf{2 0}} \mathbf{C}$ & & & \\
$\mathrm{Na}_{2} \mathrm{SO}_{4}$ & $-19,6089$ & 0,9994 & 0,0044 \\
$\mathrm{MgSO}_{4}$ & $-20,5379$ & 0,9989 & 0,0050 \\
& $\mathbf{5 0} \mathbf{C}$ & & \\
$\mathrm{Na}_{2} \mathrm{SO}_{4}$ & 2,4862 & 0,9992 & 0,0056 \\
$\mathrm{MgSO}_{4}$ & $-24,8990$ & 0,9997 & 0,0026 \\
\hline
\end{tabular}

Fonte: SigmaPlot 11.0; J.G. PIMENTEL (2015)

Percebe-se que o parâmetro de correlação $\mathrm{R}^{2}$ obteve bons resultados para o ajuste das binodais, ficando a maioria dos resultados acima de 0,999 .

Após a construção das binodais, começaram-se a determinação das linhas de amarração, sendo que em seguida ocorrerão à coleta das fases de cada sistema pesado e posterior quantificação dos componentes, álcool, sal, e água; para por fim realizar a partição da molécula de interesse. Verificando assim em qual sistema ocorreu o melhor desempenho. 
Figura 2. O gráfico superior, diagrama de equilíbrio de fases para os sistemas Álcool Isopropílico/Sulfato de sódio na temperatura de $20^{\circ} \mathrm{C}$ ( $\diamond$ e Álcool Isopropílico/Sulfato de Magnésio também na temperatura de $20^{\circ} \mathrm{C}(\bullet)$. O gráfico inferior da figura, diagrama de equilíbrio de fases para os sistemas Álcool Isopropílico/Sulfato de Sódio na temperatura de $50^{\circ} \mathrm{C}$ $(\diamond)$ e Álcool Isopropílico/Sulfato de Magnésio também na temperatura de $50^{\circ} \mathrm{C}(\bullet)$.

Binodais Álcool Isopropílico + Sulfatos $+20^{\circ} \mathrm{C}$
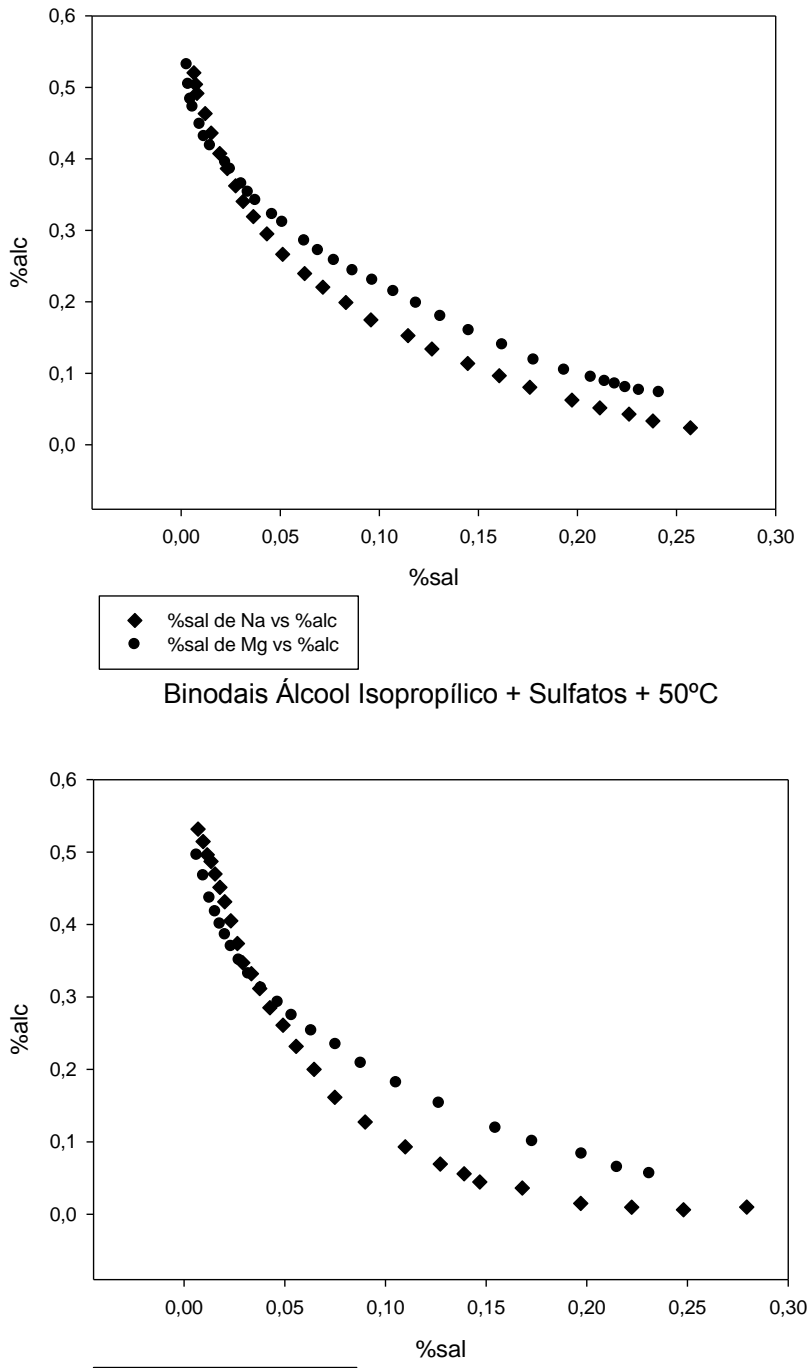

- \%sal de Na vs \%alc

- \%sal de Mg vs \%alc

Fonte: SigmaPlot 11.0; J.G. PIMENTEL (2015)

\section{CONCLUSÃO}

Com a caracterização dos sistemas aquosos bifásico, Álcool e os sulfatos $\left(\mathrm{Na}_{2} \mathrm{SO}_{4} / \mathrm{MgSO}_{4}\right)$, pode-se verificar um o ponto de equilibrio diferente nas binodais para cada uma das temperaturas de estudo, porém sem apresentar uma diferença significativa com a variação de temperatura e dos sais para as regiões bifásicas.

As posteriores conclusões ocorrerão após a determinação das linhas de amarração, sendo que após a partição da molécula, verificará a eficiência dos sistemas estabelecidos, caracterizando esse tipo de sistema aquoso bifásico uma alternativa promissora para aplicação na indústria como um tipo de tratamento de efluente terciário.

\section{REFERÊNCIAS}

ALBERTSSON, P-A. Partition of Cell Particles and Macromolecules, 2nd edition, Wiley, New York, 1986.

ALBERTSSON, P. A. Chromatography and Partiton of cells and cell fragments. Nature, v. 177, p. 771-774; 1956.

ALBERTSSON, P. A. Partition of proteins in liquid polymer-polymer two-phase systems. Nature (Lond.), v. 182, p. 709-711, 1958.

ALBERTSSON, P. Å. Nyns, E. J. Countercurrent distribution of proteins in aqueous polymer phase systems. Nature (Lond.),v. 184, p. 1465-1468, 1959.

ALI, H.; AHMED, W.; HAQ, T. Decolorization and degradation of malachite green by Aspergillus flavus andAlternaria solani. African Journal Biotechnoly, v. 8, p.1574-1576, 2009. 
ANANTHAPADMANABHAN, $\quad K . \quad P$.; GODDARD, E. D. Aqueous biphase formation in polyethylene oxide-inorganic salt systems. Langmuir. v. 3, p. 25-31, 1987.

AYDIN, H.; BULUT, Y.; YERLIKAYA, Ç. Removal of copper (II) from aqueous solution by adsorption onto low-cost adsorbents. Journal of Environmental Management, v.87, p.37-45, 2008.

BANIK, R. M.; SANTHIAGU, A.; KANARI, B.; SABARINATH, C.; UPADHYAY, S. N. Technological aspects of extractive fermentation using aqueous two-phase systems. Wold Journal. Microbiology. Biotechnology, v.19, p. 337-348, 2003.

BALAN， D.S.I., MONTEIRO, R.T.R., Decolourization of textile indigo dye by ligninolytic fungi, J. Biotechnology, v.89, p.141-145, 2001.

CARVALHO, C. P. Estudo do equilíbrio de fases para sistemas aquosos bifásicos compostos por polietileno glicol, sais e água. Dissertação de tese de mestrado. Universidade Federal de Viçosa, Viçosa, MG. UFV, 70 f.: il., 2004.

CARVALHO, C. C.; COIMBRA, J. S. R.; COSTA, I. A. F.; MINIM, L. H.; MAFFIA, M. C. Equilibrium Data for PEG 4000 + Salt + Water Systems from (278.15 to 318.15). Journal Chemycal Engeneering Data , v.52, p. 351-356, 2007.

DALLAGO, R. M.; SMANIOTTO, A.; OLIVEIRA, L. C. A de. Resíduos sólidos de curtumes como adsorventes para a remoção de corantes em meio aquoso. Química Nova, v.28, n.3 , p.433 - 437, 2005.

GETZNER, M. The quantitative and qualitative impacts of clean technologies on employment. Journal of Cleaner Production, v. 10, p. 305-319, 2002.

GUARATINI, C. I., ZANONI, M. V., Corantes Têxteis. Universidade Estadual Paulista, 1999.

GUPTA, V.K.; SUHAS. Application of lowcost adsorbents for dye removal - A review. Journal of Environmental Management, v.90, p.2313-2342, 2009.

GUO, W., MA, J., WANG, Y., HAN, J., LI, Y., SONG,S., Liquid-liquid equilibrium of aqueous two-phase systems composed of hydrophilic alcohols (ethanol/2-propanol/1propanol) and MgSO4/ZnSO4 at (303.15 and 313.15) $K$ and correlation. Thermochimica Acta. v, 546, p.8-15,2012.

HAN, J.;WANG, Y.; CHEN, C.; KANG, W.; LIU, Y.; XU, K.; NI, L.; (Liquid + liquid) equilibria and extraction capacity of (imidazolium ionic liquids + potassium tartrate) aqueous two-phase systems. Journal of Molecular Liquids, v.193, p. 23$28,2014$.

HATTI-KAUL, R. Aqueous two-phase systems: A general overview. Molecular Biotechnology, v. 19, p. 269-277, 2001.

LI, Y.J., CAO, X.J., Prediction of phase diagrams for new pH-thermo sensitive recycling aqueous two-phase systems. Fluid Phase Equilibria, v. 298, p. 206-211, 2010.

MACHADO, L. L. Utilização de Compósito Carvão/ $\mathrm{Fe}_{2} \mathrm{O}_{3}$ e Pirita como Catalisadores da Peroxidação de Efluentes Têxteis. Dissertação de mestrado. Universidade Federal de Santa Catarina, Florianópolis, 2007.

MELO, A. R. Uso integrado e eficiente da água nas indústrias têxteis catarinenses 
Tese. Florianópolis: Departamento de Química de Universidade Federal de Santa Catarina; 2008

MOATTAR-ZAFARANI, M. T., HOSSEINPOUR-HASHEMI, V., Effect of temperature on the aqueous two-phase system containing poly(ethylene glycol) dimethyl ether 2000 and dipotassium oxalate. Journal Chemycal. Engeneering. Data, v.57, p. 532-540, 2012.

MOATTAR-ZAFARANI, M. T.; NEMATIKANDE E., SOLEIMANI, A.; Study of the liquid-liquid equilibrium of 1-propanol + manganese sulphate and 2- propanol + lithium sulphate aqueous two-phase systems at different temperatures: experiment and correlation. Fluid Phase Equilibria, v.313, p.107-113, 2012.

PASCHOAL, F. M.; TREMILIOSI-FILHO, G. Aplicação da tecnologia de eletrofloculação na recuperação do corante Índigo Blue a partir de efluentes industriais. Química Nova, São Paulo, v. 28, n. 5, p. 766-772, jun. 2005.

PEREIRA, V.A.L. Dissertação de mestrado, Universidade Federal de Viçosa, 2008.

REIS, I. A. O.; Lima, A. S.; Soares, C. M. F.; SANTOS, S. B. Aplicacao de sistemas aquosos bifasicos na extracao de biomoleculas. In: Antonio Martins de Oliveira Junior; Ana Carolina Sampaio Doria Chaves; Tatiana Pacheco Nunes. (Org.). Alimentando o Conhecimento. $1^{\mathrm{a}} \mathrm{ed}$. São Cristovao - SE: Editora UFS, v. 1, p. 83-104. 2012,

ROGERS, R. D., WILLAUER, H. D., GRIFFIN, S. T., HUDDLESTON, J. G. Partitioning of small organic molecules in aqueous biphasic systems. Journal. Chromatografy. B, v. 711, p.255-263, 1998.
SAUER, T. Degradação fotocatalítica de corante e efluente têxtil. Dissertação. Florianópolis: Departamento de Química da Universidade Federal de Santa Catarina; 2002.

TIANWEI, T., QING, H., QIANG, L., Purification of glycyrrhizin from Glycyrrhiza uralensis Fisch with ethanol/phosphate aqueous two phase system. Biotechnology Lett.; v. 24, p.141720, 2002

TOH, Y. C., YEN, J. J. L., OBBARD, J. P., TING, Y. P., Decolourization of azo dyes by white rot fungi (WRF) isolated in Singapore, Enzyme Microbial Technology v.33, p.569-575, 2003.

XIE, X.Q., YAN, Y.S., HAN, J., WANG, Y., YIN, G.W., GUAN, W.S., Liquid liquid equilibrium of aqueous two-phase systems of PPG400 and biodegradable salts at temperatures of $(298.15,308.15$, and 318.15) K, Journal Chemycal Engeneering Data, v. 55, p.2857-2861, 2010.

WANG, Y., YAN, Y.S., HU, S.P., HAN, J., $\mathrm{XU}, \mathrm{X} . \mathrm{H}$., Phase diagrams of ammonium sulfate ethanol/1-propanol/2-propanol water aqueous two-phase systems at $\mathbf{2 9 8 . 1 5}$ $K$ and correlation, Journal Chemycal Engeneering Data, v. 55, p. 876-881, 2010.

ZYAN, F., J. Q. LI, X. SUN, SUN, L., CHEN, J.; Liquid-Liquid equilibria of aqueous systems containing alcohol and ammonium sulfate; Fluid Phase Equilibria, v. 317, p.1-8, 2012. 